\title{
WALLENSTEIN, DINASTÍA VASA Y ARMADA HISPANO-POLACA EN EL MAR BÁLTICO, 1628-1632. LAS ACCIONES DE LA ARMADA HISPANO-POLACA ENTRE LOS AÑOS 1629-1632 Y SU DESTRUCCIÓN
}

\author{
Karel Staněk \\ Biblioteca Nacional de Praga, República Checa \\ kar.stanek@volny.cz \\ Michal Wanner \\ Department of Archives Administration and Records Management of the \\ Ministry of the Interior, República Checa \\ michal.wanner@seznam.cz
}

RESUMEN: En este estudio, analizamos principalmente las operaciones de la armada hispano-polaca contra los daneses y suecos entre los años 1629 y 1632, o sea, desde el fin de la Guerra Danesa y el inicio de la Guerra Sueca hasta la conquista de Wismar por el ejército sueco y la destrucción de la armada en enero de 1632. Al final, intentamos evaluar la influencia y el impacto de la armada hispano-polaca en el Mar Báltico de manera global.

Palabras clave: España, Polonia, Alberto de Wallenstein, Mar Báltico, armada hispano-polaca.

\section{WALLENSTEIN, VASA DYNASTY AND SPANISH-POLISH FLEET IN THE BALTIC SEE, 1628-1632. ACTIONS OF SPANISH-POLISH FLEET BETWEEN 1629-1632 AND ITS DESTRUCTION}

ABSTRACT: In this study, we analyse particularly the operations of the Spanish-Polish fleet against the Danes and the Swedes between 1629 and 1632, that is, from the end of the Danish War and the beginning of the Swedish War to the conquest of Wismar by the Swedish army and to the destruction of the navy in January 1632. In the end, we tried to assess in a 
global way the influence and impact of the Spanish-Polish fleet on the Baltic Sea.

Keywords: Spain, Poland, Albert of Wallenstein, Baltic Sea, Spanish-Polish fleet.

Recibido: 23 de agosto de 2018 Aceptado: 31 de agosto de 2019

Este trabajo representa una continuación del estudio dedicado al origen y a la formación de la armada española-polaca en el Mar Báltico que ya fue publicado en las páginas de esta revista. La primera parte se refirió al análisis de los objetivos políticos de España, Polonia y el emperador en el Mar Báltico entre los años 1628 y 1629, y de los métodos usados por ellos. La descripción de la construcción de la armada española en el Mar Báltico, los problemas a los que los españoles se enfrentaban, y finalmente la formación de la armada conjunta española-polaca en Wismar en febrero de 1629, fueron también una parte integral del primer estudio. En la segunda parte, analizaremos principalmente las acciones de la armada contra el enemigo danés y sueco en el final de la Guerra Danesa y el inicio de la Guerra Sueca hasta la conquista de Wismar por el ejército sueco, concluyendo con la extinción de la armada en enero de 1632. Al final, intentaremos evaluar este fenómeno de manera global.

\section{Las acciones de la armada hispano-polaca contra Dinamarca}

Enfrente del puerto de Wismar, desde su ocupación por el ejército imperial, los buques daneses cruzaban incesantemente. Poco después de que Mansfeld hubiera asumido el comando de la armada, ésta sufrió la primera derrota. El 24 de abril de 1628, siete buques que estaban fondeados en Greifswald fueron atacados y destruidos en Wieck por cuatro buques de guerra daneses. Esto resultó en la destrucción del núcleo de la armada de Wallenstein, la cual tuvo que ser construida de nuevo. ${ }^{1}$ Además de eso, los daneses enviaban sloops a la ciudad para que secuestraran barcos de pesca locales. ${ }^{2}$

El segundo ataque danés ocurrió en junio y julio de 1628. El 24 de junio por la tarde un buque de guerra apareció enfrente de la isla de Poel, en la bahía de Wismar. Más tarde, el 1 de julio, dos barcos más junto con un bojort y dos sloops entraron en la bahía. El bojort se acercó a la bahía y desde allí disparó

1. Pertek, Jerzy, Flota polska w Wismarze (1629-1632), Przegład Zachodni 10, 1954, n. 7/8, p. 421.

2. Wahrlich, Bernd, Der Dreißigjährige Krieg in Selbstzeugnissen, Chroniken und Berichten, Mansfeld-Vorderort zu Bornstedt, Philipp (V.) Graf von (fuente electrónica). 
balas de hierro contra el puerto y contra un galeón imperial (Orlogshiff). También consiguió derribar las vergas de su mástil mediano. Asimismo, los edificios portuarios sufrieron daños. Varios techos y gabletes fueron dañados, una de las balas penetró en la Puerta de Agua, y la otra impactó en la pared enfrente de ella. Al mismo tiempo, los daneses bloquearon la entrada al puerto con dos botes, en cuyo fondo colocaron pesadas barras metálicas. Los ataques continuaron en los días siguientes, pero no se produjo un ataque decisivo. El 10 de julio, dos sloops daneses atacaron el puerto, lo que resultó en la muerte de dos pescadores. Por su parte, el 18 de julio, los buques de Wallenstein hicieron una salida, pero fueron repelidos por un galeón danés. Sin embargo, se apoderaron del sloop cuya tripulación, supuestamente, rescataron de la muerte. Otro ataque imperial valiente ocurrió el 24 de julio, pero no tuvo éxito. ${ }^{3}$

Según la Crónica de Wismar, el 4 de octubre tres buques de guerra daneses llegaron y se quedaron 14 días enfrente de la isla Poel, donde los daneses capturaron a algunos pescadores y los Ilevaron a Copenhague. Wismar tuvo que pagar más tarde 100 ducados por su liberación. El 9 de noviembre, un galeón imperial zarpó del puerto acompañado por un buque pequeño y durante 8 días se apoderó de un botín importante compuesto de lino y sal. El 1 de diciembre, los buques imperiales supuestamente asaltaron un buque de guerra danés en Travemünde y consiguieron capturar un sloop danés "con una presa bella". El buque de guerra danés atacó a los buques imperiales en su camino de regreso, matando a varios marineros. ${ }^{4}$

La armada desempeñó un papel considerable en las negociaciones sobre la paz de Lübeck. Estas negociaciones tenían lugar en Nordstrand. Fueron complicadas porque al principio ambas partes planteaban demandas poco realistas. Cristiano IV rechazó que las negociaciones de paz derivasen en una tregua, como exigía y ofrecía Wallenstein, y en vez de eso realizaba acciones militares que se pueden calificar como una demostración de poder. En resumen, intentaba persuadir a su enemigo de que todavía no estaba completamente derrotado. El 31 de marzo de 1629, Cristiano IV salió con una armada de guerra. La armada danesa, que constaba de 14 buques, llegó a la rada de Wismar el 2 de abril de 1629 y bombardeó el puerto, intentando bloquearlo. El buque imperial Wahlfish le hacía frente. El ataque danés fue finalmente repelido, ya que fue alcanzado principalmente por los buques polacos. Los daneses, que aseguraron sus refuerzos, no se atrevieron a repetir el ataque y se limitaron a fortalecer la protección de sus líneas navales. ${ }^{5}$

Después, Cristiano IV, con el consentimiento del Consejo de Estado, preparaba el ataque a Jutlandia, tanto desde el oeste como desde el este. En la

3. Wahrlich, Bernd, Der Dreißigjährige Krieg (fuente electrónica).

4. Wahrlich, Bernd, Der Dreißigjährige Krieg (fuente electrónica).

5. Koczorowski, Eugeniusz, Flota polska v latach 1587-1632. Varsovia 1973, p. 349. 
segunda mitad de mayo, el general Morgan, todavía en los servicios ingleses, salió de Glückstadt y se apoderó de la isla de Nordstrand. Luego desembarcó y ocupó varios lugares, el más importante de ellos fue Tonderen. Sin embargo, se encontró con la resistencia imperial que era probablemente mayor de lo que esperaba. Su ataque contra Husum fue repelido. El 29 de mayo el rey salió con fuerzas considerables de la isla Fionia (Fyn), desembarcó en la costa este de Holstein y marchó hacia Schleswig. Sin embargo, no consiguió unirse con el ejército de Morgan, que era su objetivo. Por lo tanto, su campaña terminó en fracaso. Wallenstein, al principio, subestimó la operación militar danesa porque se concentraba más en las conversaciones de paz, pero no fue difícil para él agrupar sus fuerzas y preparar otra derrota para el rey danés. ${ }^{6}$ En Holstein, se luchó ferozmente hasta que se alcanzó la paz. ${ }^{7}$

A principios de junio de 1629, Wallenstein pidió, a instancias de Torquato Conti y Gabriel de Roy, que varios buques salieran lo más pronto posible, sin duda para enfrentarse a los buques daneses. ${ }^{8}$ Sin embargo, en breve fue oficialmente declarada la paz de Lübeck y las hostilidades en el mar terminaron, y los buques no zarparon. El 1 de junio los delegados daneses recibieron un consentimiento escrito del rey, el 4 de junio Wallenstein y Tilly firmaron el acuerdo y el 5 de junio ambas partes intercambiaron los documentos respectivos. El 6 de junio, ambas partes estuvieron de acuerdo en que la paz se anunciaría de modo festivo al día siguiente, 7 de junio, tocando las campanas, y que las hostilidades en tierra y en mar cesarían el 11 de junio. ${ }^{9}$ Los documentos ratificados fueron intercambiados entre el emperador y el rey en Lübeck el 2 de julio de 1629. El emperador agradeció a Wallenstein en una carta del 14 de julio su esfuerzo por conseguir el acuerdo de paz. ${ }^{10}$

Cristiano IV evadió las pérdidas porque todos los territorios ocupados por el ejército imperial debían serle devueltos inmediatamente. Esto fue, entre otras cosas, consecuencia de la débil posición del partido imperial en el mar, donde

6. Más detalladamente Wallenstein a Collalto 31. 5. 1629. Aldringen le aconsejó que devastara Jutlandia y lo evacuara, pero Wallenstein no lo quería hacer debido a las negociaciones de paz. Chlumecký, Petr Jiř́, Die Regesten oder chronologische Verzeichnisse der Urkunden in den Archiven zu Iglau, Trebitsch, Triesch, Gross.Bitesch und Pirnitz, sammt den noch ungedruckte Briefen Kaisers Ferdinand der Zweiten, Albrechts v. Waldstein und Romboalds Grafen Collalto. Brno 1856, n. 217, p. 134. Sin embargo, en las cartas de Wallenstein a Collalto de 2. 6. y 6. 6. 1629, Wallenstein declaró su voluntad de dar al rey danés una dura lección. Chlumecký, Die Regesten, n. 219, p. 137; n. 224, p. 143.

7. Sobre el curso de estas negociaciones Conti a Wallenstein 5. 6. 1629, NA VL F 67/52. Opel, Julius Otto, Der niedersächsisch-dänische Krieg, vol. I-III. Magdeburg 1872-1894, vol. III, pp. 740-744.

8. Wallenstein a Gabriel de Roy 2. 6. 1629 DBBT 4, n. 772, p. 300.

9. Wallenstein al emperador 4. 6. 1629, NA VL F 67/49; Aldringen a Wallenstein 5. 6., 6. 6. y 7. 8. 1629, VL F 67/52, DBBT IV, n. 778, p. 302.

10. NA VL F 67/49, n. 783, p. 303. 
no había sido apoyado de manera suficiente por España. La Corona española rechazó entregar la Armada de Flandes a Wallenstein. Olivares estaba irritado por la subordinación de Gabriel de Roy frente a Wallenstein, en quien no confiaba. El Consejo de Estado quería dirigir los buques principalmente contra los holandeses y los suecos, pero la situación se les fue de las manos a los españoles y los buques continuaron bajo el control de Wallenstein. Esto llevó tanto a la búsqueda de aliados alternativos en el Mar Báltico -primero en Schleswig-Holstein, más tarde en Dinamarca-, como a las consideraciones de la retirada de los buques a España. ${ }^{11}$ Pero quedaba la cuestión de cómo continuaría la situación en caso de que los españoles obtuvieran el control directo sobre la armada. Sin embargo, el comienzo de la guerra con Suecia era poco probable porque España tenía problemas financieros y ninguna de las partes quería poner en peligro los contactos comerciales mutuamente beneficiosos. ${ }^{12}$

Tampoco las ciudades hanseáticas ofrecieron ayuda a los españoles. La razón fue la discrepancia entre la Hansa y los españoles. No se trataba solo de una renuncia a participar en la compañía hanseático-ibérica; las ciudades se negaron a aceptar residentes españoles y a otorgar certificados para el comercio con España. Los españoles intentaron impedir la importación de bienes holandeses camuflados entre las mercancías hanseáticas. Por lo tanto, los artículos debían contener un certificado de su origen que debía ser emitidos por los residentes españoles en las ciudades hanseáticas, subordinadas a la Junta de Almirantazgo. Los españoles también querían evitar que la Hansa utilizara buques holandeses en el comercio con España. Sin embargo, los comerciantes hanseáticos rechazaban tal subordinación de su comercio a las demandas españolas y amenazaban con reorientar su comercio a otros territorios. Además, desde enero de 1627, la Junta requería las fianzas para garantizar que las mercancías exportadas de España no se dirigiesen a los puertos holandeses. No obstante, la Hansa solo estaba dispuesta a aceptar las declaraciones juradas. Los españoles introdujeron sus medidas repetidamente entre los años 1627-1632, pero seguidamente las anulaban por miedo a que el comercio español-hanseático fuera interrumpido. $^{13}$

La intervención diplomática francesa en la región, la amenaza de que Suecia entrara en guerra y el apoyo sueco a Stralsund, jugaron un papel importante

11. Israel, Jonathan I., The Politics of International Trade Rivalry during the Thirty Years War: Gabriel de Roy and Olivares'Mercantilist Projects, 1621-1645, The International History Review 8, 1986, n. 4, pp. 533-535, 541-542; Israel, Jonathan I., Empires and Entrepots: The Dutch, the Spanish Monarchy and the Jews 1585-1713, London, Ronceverte 1990, pp. 213-246.

12. Mörner, Magnus, Las relaciones Hispano-Suecas ante la paz de Wesfalia, Historiar: Revista trimestral de Historia, 1999, n. 1, pp. 124-126.

13. Israel, Jonathan I., The Politics of International Trade Rivalry during the Thirty Years War: Gabriel de Roy and Olivares'Mercantilist Projects, 1621-1645, pp. 517-518, 527-531, 536541. 
durante las negociaciones de paz en Lübeck. Los españoles suscribieron la paz para poder liberar las manos del emperador en el norte y obligarle a intervenir militarmente en las Provincias Unidas. El interés personal de Wallenstein, como duque de Mecklemburgo, de dar la mayor seguridad posible a este ducado también era un estímulo importante para conseguir la paz. ${ }^{14}$

Las negociaciones de paz culminaron, supuestamente, en una escena que se describe mucho en la literatura, pero sin comentarios ni citaciones de fuentes. ${ }^{15}$ Según las descripciones, después de haber concluido la paz de Lübeck, WaIlenstein envió a su emisario en una galera imperial para reunirse con Cristiano IV, pidiéndole que permitiera el paso de los buques imperiales por Sunda. El rey danés lo rechazó y contestó al emisario que "el Mar Báltico reconoce solo las banderas danesa y sueca". Después mandó encarcelar al emisario. Igualmente, el rey sueco Gustavo Adolfo II rehusó reconocer el título de Wallenstein como "General del Mar Océano y Báltico". Las tentativas de Wallenstein después de haber concluido la paz de Lübeck de abrir Sund para que los barcos imperiales pudieran salir hacia los Países Bajos Españoles da sentido a la lógica de los acontecimientos, sin embargo, la falta de una fuente fiable hace la escena descrita poco probable.

Ya en la primera mitad de septiembre de 1629, Segismundo III exigió a Wallenstein devolver los buques polacos y enviarlos a Gdansk. Wallenstein se refirió a Roy como la persona que se había hecho cargo de la armada, y le aconsejó pedir al emperador que resolviera este asunto. El diplomático español se mostró rotundamente en contra de la entrega de los buques polacos al rey de Polonia. En octubre presentó a la corte de Viena algunas propuestas, para nosotros poco conocidas, en relación con la armada polaca, pero el emperador las rechazó. El emperador ordenó poco después, ya tras la firma de la tregua polaco-sueca de Altmark de 26 de septiembre de 1629, enviar la armada a Gdansk y entregarla a los comisarios de Segismundo III. ${ }^{16}$ Sin embargo, Roy no cumplió las órdenes de Fernando II, lo que forzó a Segismundo III a intervenir inmediatamente en la corte de Madrid.

\section{Conflicto con los suecos}

Inmediatamente después de haberse firmado la paz entre el emperador y Dinamarca en Lübeck, y de haber salido la armada danesa de Wismar, Gustavo

14. Rodenas Vilar, Rafael, La política europea de España durante la guerra de los Treinta Años (1624-1630). Madrid 1967, pp. 187, 201-202.

15. Koczorowski, Flota polska, p. 350; Pertek, Flota polska, p. 428; Bei der Weiden, Helge, Wallenstein und die kaiserliche Ostseeflotte 1627-1632 aus tausend Jahren mecklenburgischer Geschichte. Colonia-Viena 1979, p. 85 y otros.

16. Fernando II a Wallenstein, Viena 1. 11. 1629, y Fernando II a Gabriel de Roy, Viena 1. 11. 1629, DBBT, parte 4, n. 878, p. 336; Letošník, Václav, Polsko, dům Rakouský a Albrecht z Valdštejna 1626-1629, Časopis Českého muzea 111, 1937, p. 220. 
Adolfo II cambió la base de sus fuerzas navales de los puertos de Suecia del Este y de la bahía de Gdansk a los puertos en Pomerania Occidental y Mecklemburgo. A principios de junio de 1629, Klas Fleming recibió una orden de construir seis buques en Estocolmo, destinados a bloquear Wismar. Juan Banér, que estaba en ese momento en Prusia Real, debía acaudillar la escuadra. Al mismo tiempo, el rey de Suecia ordenó que los 16 buques mayores, preparados para la guerra, se reunieran en Dalarö y estuvieran disponibles para Klas Fleming. En total, seis buques suecos fueron enviados a Kalmar. ${ }^{17} \mathrm{~A}$ mediados de junio, Gustavo Adolfo II cambió sus planes. Nombró a Erik Ryning en lugar de Juan Banér y le encargó formar una escuadra de buques bajo el mando de Hans Horn para bloquear Wismar. A comienzos de julio, Ryning salió de Piława con la escuadra, compuesta por los buques Apollo, Andromeda, Papegojan, Swarta Hunden y Storken, a la que se unió un poco más tarde el buque Regnbogen. Simon Stewart, un hombre experimentado, debía aconsejar a Ryning, quien anteriormente ocupó el cargo del gobernador sueco en Prusia Real y no era ningún experto en la guerra naval. ${ }^{18}$ Además, el rey de Suecia mandó construir una escuadra más y enviarla a la bahía de Gdansk para que pudiera impedir el bloqueo de Piława cuando Ryning atacase la armada polaco-imperial. ${ }^{19}$

Después de haber acordado la paz con Cristiano IV, Wallenstein ordenó parar las acciones militares contra los daneses tanto en tierra como en el mar. ${ }^{20} \mathrm{Sin}$ embargo, autorizó una propuesta para un ataque contra Stralsund. ${ }^{21}$ En realidad esto significó comenzar una guerra contra la armada sueca que abastecía la ciudad, o sea, contra la tripulación sueca dentro de ella. ${ }^{22}$ Sin embargo, los suecos fueron más rápidos y a fines de julio los buques suecos aparecieron enfrente de Wismar. La tarea del almirante Erik Ryning consistía en bloquear tanto Wismar como los buques imperiales y polacos allí anclados. Además de eso Ryning debía proteger las rutas marítimas suecas en la zona del Mar Báltico del Oeste junto con una escuadra bajo el comando de Peter Blume que estaba en Stralsund. ${ }^{23}$ Los suecos capturaron dos buques mercantes pequeños de Wismar, pero ya en la primera quincena de agosto se fueron, por lo tanto la armada imperial no consiguió cumplir a tiempo una orden de Wallenstein y hacerse a la mar. ${ }^{24}$

Por una orden de Wallenstein, la salida de la armada de Wismar estaba preparada en conjunto por el comisario general Roy, coronel Hatzfeld (comandan-

17. Koczorowski, Flota polska, p. 353.

18. Koczorowski, Flota polska, p. 353.

19. Zettersten, Axel, Svenska flottens historia áren 1522-1634. Estocolmo 1890, p. 491.

20. Wallenstein a Roy 8. 6. y a Mansfeld 13. 6. 1629, NA VL 67/50.

21. Wallenstein a Hatzfeld 10. 6. 1629, NA VL 67/50.

22. Roy a Wallenstein 11. 7. 1629, NA VL 67/52.

23. Pertek, Flota polska, p. 429.

24. Wallenstein al comandante en Wismar 27. 8. 1629, NA VL 67/50; Hatzfeld a Wallenstein 8. 8. 1629, NA VL 67/52; Wengersky a Wallenstein 6. y 11. 8. 1629, NA VL 67/52. 
te militar en Pomerania), coronel Wengersky (comandante militar en Mecklemburgo) y teniente coronel Dewogkhy (comandante de la guarnición en Wismar), pero difícilmente llegarían a un acuerdo. Estos oficiales acusaron a Roy de vacilación, flojedad y pérdida del momento adecuado para atacar. Es posible que una de las razones fuese la mala salud de Roy, que estaba gravemente enfermo en septiembre. Fue particularmente criticado por Hatzfeld, quien le pedía a Roy que ordenara que salieran al menos las embarcaciones pequeñas, si no era capaz de enviar los buques de guerra. También Wengersky y Dewogkhy aconsejaron a Roy atacar. ${ }^{25}$ Además de eso, Wengersky criticó duramente el estado de las tripulaciones y la postura de Roy: "Solo se trataba de tripulaciones insignificantes y malas. Roy carecía de marineros. Según los informes de capitanes navales podría recibirlos si los quisiera reclutar, pero él no quería formar tripulaciones inmediatamente. Esto ahorrará unos pocos táleros, pero no se logrará nada." ${ }^{26}$ Mientras tanto Wallenstein, a petición de Roy, estaba buscando un comandante naval apto. Lo encontró en el capitán Rogier (también conocido como Roger), quien fue a Wismar junto con los marineros de Wolgast. ${ }^{27}$

Cuando en septiembre de 1629 los buques suecos volvieron a aparecer frente a Wismar, ${ }^{28}$ Wallenstein ordenó a Roy que los atacara. La presencia de esos buques le molestaba a Wallenstein tanto más cuanto que en el mismo momento le Ilegaron las noticias de que Gustavo Adolfo II planeaba desembarcar en Stralsund un ejército de entre 10000 y 12000 soldados. Por esta razón envió una parte de su ejército a Stralsund y pidió refuerzos de Tilly. ${ }^{29}$ El 5 de septiembre el coronel Wengersky debía lanzar los buques al mar. A mediados de septiembre el teniente coronel Dewogkhy informó de que a las órdenes de los dos coroneles había reunido 600 hombres al mando del capitán Rogier, y que estaban listos para embarcar. Rogier se convirtió en el comandante de esta escuadra. El resto de actividades preparatorias se llevaron a cabo rápidamente. El 18 de septiembre Wengersky informó de que enfrente de Wismar estaban todavía trece buques suecos, los cuales serían, en su opinión, fáciles objetivos de ataque porque tenían tripulaciones de mala calidad. Sin embargo Roy aún no estaba preparado para el ataque porque le faltaban marineros. Dado que quería ahorrar algún dinero, rechazó contratar las tripulaciones paso a paso, y se decantó por reclutarlas todas juntas. ${ }^{30}$ El 24 de septiembre, Roy informó a Wallenstein de que su armada estaba finalmente lista, las tripulaciones estaban embarcadas

25. Hatzfeld a Wallenstein 28. 8. 1629, NA VL 67/52.

26. Wengersky 18. 9. 1629, NA VL 67/52, DBBT IV, n. 837, p. 320.

27. Wallenstein a Roy 28. 7. y 29. 7. 1629 1629, NA VL 67/50.

28. Dewogkhy a Wallenstein 3. 9. y 16. 9. 1629, NA VL 67/52.

29. Wallenstein a Roy 21. 6. 1629, a Tilly 6. 9. 1629, NA VL F 67/50.

30. Wallenstein a Wengersky 5. 9. 1629, NA VL F 67/50; Wengersky a Wallenstein 12. a 18. 9. 1629, NA VL F 67/52; Dewogkhy a Wallenstein 16. 9. 1629, Hatzfeld a Wallenstein 23. 9. 1629 VL F $67 / 52$. 
y los buques zarparían en breve para enfrentarse a los buques suecos anclados delante del puerto. ${ }^{31}$

Al principio uno de los buques imperiales intentó romper el bloqueo, pero los suecos lo vencieron gracias a su superioridad numérica. ${ }^{32}$ Probablemente el 29 de septiembre seis buques se hicieron a la mar para ir contra la escuadra sueca, al mando del coronel Erik Ryning. Una escaramuza naval ocurrió antes de que los buques suecos pudieran levar el ancla y salir de la rada de Wismar. Se trata de la única batalla entre las escuadras imperial y sueca durante toda la guerra. Su resultado es cuestionable. De acuerdo con Gabriel de Roy, los buques imperiales obtuvieron una gran victoria y expulsaron a la armada sueca de Wismar. ${ }^{33}$ Wengersky solo declaró secamente que los buques suecos habían salido por la noche del 30 de septiembre. ${ }^{34}$ Según Khevenhüller, los buques imperiales fueron rechazados, pero a pesar de eso los suecos partieron. ${ }^{35}$ Fuera como fuera, lo cierto es que el bloqueo se rompió y Ryning salió a Kalmar. ${ }^{36}$ La costa de Wismar estuvo libre hasta principios de noviembre, momento en que se restableció el bloqueo. ${ }^{37}$

Los buques imperiales capturaron varios prisioneros durante la batalla, incluido el comerciante holandés Willem Usselinx, inspirador de la Compañía Holandesa de las Indias Occidentales y fundador y director de la Compañía Sueca del Mar del Sur. ${ }^{38}$ Fue interrogado por Roy, pero liberado al poco tiempo por orden de Wallenstein, al igual que los otros prisioneros. ${ }^{39}$

31. Roy a Wallenstein 24. 9. 1629 y Roy a Wallenstein 23. 9. 1629, NA VL F 67/52.

32. Roy a Wallenstein 3. 10. 1629, NA VL 67/52; Véase también Declaración de Gustavo Adolfo sobre la defensa del mar enfrente de Stralsund, LÍVA, Prameny $k$ dějinám třicetileté války - Regesta Fondu Militare, parte IV. 1626-1635. Praga 1953, p. 248.

33. Roy a Wallenstein 3. 10. 1629, NA VL F 67/52.

34. Wengersky a Wallenstein 30. 9. 1629, NA VL 67/52.

35. Khevenhüller, Franz Christoph, Annales Ferdinandei, Annales Ferdinandei Oder Wahrhaffte Beschreibung Kaysers Ferdinandi Des Andern, Mildesten Gedächtniß, Geburth, Aufferziehung und bißhero in Krieg und Friedens-Zeiten vollbrachten Thaten, geführten Kriegen, und vollzogenen hochwichtigen Geschäfften. 12. ..., darinnen Kaeysers und Koenigs Ferdinand ... Handlungen wegen ... Kriege in Deutschland ... wie auch alle denckwuerdige Geschichte ... vom Anfange des 1632. biß zu Anfang des 1637. Jahrs beschrieben werden, vol. 11, 1726, p. 783.

36. Roy a Wallenstein 3. 10. 1629, NA VL F 67/52; Wengersky a Wallenstein 30. 9. 1629; NA VL F 67/52; Hroch, Miroslav, Valdštejnova politika v severním Německu v letech 16291630, Sborník historický 5, 1957, pp. 215-216; Sveriges krig III, p. 110 (el acontecimiento es aquí descrito erróneamente como si Ryning rechazara los buques imperiales al puerto).

37. Roy a Wallenstein 4. 11. 1629, NA VL 67/52.

38. Olán, Eskil, Ostindiska Compagniets Saga. Historien om Sveriges Märkligaste Handelsföretag, Göteborg 1920, pp. 7-8; Kjellberg, Sven T., Svenska Ostindiska Compagniet, in: Svenska Kulturbilder III, 1930, p. 68; Kretschmar, Johannes, Schwedische Handelskompanien und Kolonisationsversuche im sechzehnten und siebzehnten Jahrhundert, in: Hansische Geschichtsblätter XVII, 1911, p. 238.

39. Israel, Jonathan I., The Politics of International Trade Rivalry during the Thirty Years War, p. 535. 
Wallenstein consiguió romper el bloqueo sueco de Wismar, aunque solo temporalmente, lo que es legítimo considerar, sin duda, como un éxito en el desempeño de su cargo de duque de Mecklemburgo y "General del Mar Océano y Báltico". Sin embargo, si atribuyéramos la victoria solo al poder de la armada imperial, sería una sobreestimación inadecuada, ya que la armada sueca podía restituir el bloqueo de Wismar en cualquier momento. Wallenstein aprovechó la posibilidad de promover el comercio libre en el Mar Báltico, lo cual autorizó en julio para todos los buques bajo su protección. ${ }^{40}$ Sin embargo, sus comandantes subordinados comenzaron a ejercer la piratería. En unos pocos días capturaron al menos diez buques mercantes que navegaban cerca de Wismar. En total, sabemos de la detención de tres buques suecos que transportaban mercancía, dos buques suecos que transportaban tropas, dos buques de Lübeck, un buque holandés y otros tres buques cuya carga no se especifica. ${ }^{41}$

No todos los miembros del almirantazgo imperial pensaban de la misma manera. Mansfeld renunció el 18 de julio 1629 a su cargo de almirante, regresó a Flandes y fue sustituido por Gabriel de Roy, que se convirtió en el comandante imperial. Su tarea consistía en la supervisión de la construcción de una armada, si bien precisamente él era quien lideraba la piratería. ${ }^{42}$ Sus actividades en ese sentido resultaban paradójicas, ya que Wallenstein lo nombró 'comisario imperial' el 9 de agosto de 1629 y le encomendó la protección del comercio y para equipamiento de los buques. ${ }^{43}$ Roy ordenó controlar el comercio en Wismar, lo que estaba pensado principalmente contra la mercancía "hostil" y contra el transporte de mercancía para los puertos enemigos. Sin duda, Roy procedió de acuerdo con la política española dirigida contra los holandeses, pero el resultado fue un poco confuso. No estaba claro qué puertos y qué productos se consideraban hostiles, pero el sistema de inspecciones e investigaciones, respaldado por los juramentos, fue elaborado rigurosamente. A pesar de su engorrosa burocracia, el sistema no era seguro y se asemejaba a las inspecciones de los buques mercantes en los puertos españoles. No es extraño, por lo tanto, que Wallenstein no hubiera aprobado la propuesta. A principios de noviembre, esta decisión fue refrendada por el emperador. ${ }^{44}$

Sin embargo, Roy continuó con sus actividades y ordenó al capitán Rogier que persiguiera a los buques mercantes suecos, hanseáticos y holandeses. ${ }^{45} \mathrm{De}$

40. Una patente de Wallenstein de 27. 7. 1629, NA VL 67/50.

41. Dewogkhy a Wallenstein 30. 9. 1629, NA VL 67/52; Wallenstein a Roy 6. 10. 1629, NA VL 67/50; Khevenhüller, Annales Ferdinandei, vol. XI, p. 783; Los inventarios de 8 de los buques detenidos forman un anexo de la carta de Wengersky a Wallesntein de 20. 10. 1629.

42. Jonathan Israel entendió esta actividad como un intento de Gabriel de Roy para demostrar su independencia con respecto a Wallenstein.

43. Wallenstein a Roy 9. 8. 1629, NA VL 67/50.

44. Emperador a Wallenstein 1. 11. 1629, NA VL 67/51.

45. Wallenstein a Wengersky 4. 10. 1629, NA VL 67/50. 
esta manera procedía totalmente en contra de la doctrina del comercio libre que había sido ordenada por Wallenstein. Roy se apoderaba de la carga de los buques capturados y estaba listo para venderla. ${ }^{46}$ Cuando el comandante de la guarnición en Wismar, Dewogkhy, expresó su desacuerdo con este procedimiento, Roy se quejó a Wallenstein. ${ }^{47}$

Solo las órdenes de Wallenstein acabaron con los asaltos a los buques mercantes. Wallenstein censuraba a Roy repetidamente, ${ }^{48}$ prohibía nuevas incursiones y añadía: "Si impidiéramos el comercio, no lograríamos nada bueno. Además, nuestra intención nunca fue atacar a los buques mercantes, sino solo a los buques de guerra que estaban frente al puerto." ${ }^{49}$ Por lo tanto, Wallenstein encargó a Wengersky que liberara todos los buques y devolviera los bienes a los mercaderes. ${ }^{50}$ Dewogkhy debía supervisar este procedimiento. Además, fue elogiado por haber impedido a Roy confiscar y vender la mercancía de los buques. $^{51}$

Roy tuvo que liberar los buques mercantes en octubre de 1629, después de la intervención de Wallenstein. ${ }^{52}$ Además, Wallenstein aseguró al consejo municipal de Lübeck que los ataques no continuarían. Ordenó expresamente que los buques hanseáticos no debían ser molestados por la armada imperial. ${ }^{53}$ También el rey danés Cristiano IV se quejó de la violación del comercio libre, pero su queja no llegó a tiempo, sino el 26 de noviembre de 1629, cuando Wallenstein ya había implementado las medidas mencionadas. ${ }^{54}$

Wallenstein estaba totalmente en contra la piratería, la cual, como enfatizaba, no era digna de un soldado. ${ }^{55}$ Anunció a los marineros despedidos que el duque de Friedland y Mecklemburgo les garantizaba una plena libertad del comercio y que no toleraría la piratería realizada por los buques imperiales. ${ }^{56}$ Wallenstein escribió también al rey danés que no le gustaba la piratería y que ni él ni su país se beneficiaban de ella de ninguna manera. Incluso declaró que no dejaría armar ni zarpar buques imperiales si los suecos entorpecían el comercio marítimo. Sin embargo, expresó que se vería obligado a intervenir contra los buques suecos si continuaban perturbando el comercio frente a la costa de Wis-

46. Dewogkhy a Wallenstein 30. 9. 1629, NA VL 67/52.

47. Wallenstein a Wengersky 14. 10. 1629, NA VL 67/50.

48. Wallenstein a Roy 4. 10., 6. 10., 9. 10. 1629, NA VL 67/50.

49. Wallenstein a Roy 9. 10. 1629, NA VL 67/50.

50. Wengersky a Wallenstein 10. y 12. 10. 1629, NA VL 67/52.

51. Wallenstein a Roy 12. y 14. 10. 1629, NA VL 67/50.

52. Roy a Wallenstein 15. 10. 1629, Wengersky a Wallenstein 15. 10. 1629, NA VL 67/52.

53. Líva, Prameny $k$ dějinám třicetileté války - Regesta Fondu Militare, parte IV. 16261635. Praga 1953, p. 244.

54. Cristiano IV a Wallenstein 14. 10. 1629, NA VL $67 / 52$.

55. Wallenstein Wengersky 4. 10. 1629, NA VL 67/50.

56. Wallenstein Wengersky 12. 10. 1629, NA VL 67/50. 
mar. ${ }^{57}$ Cabe destacar que en todos los casos mencionados Wallenstein actuaba como el duque de Mecklemburgo y promovía el desarrollo de sus puertos y del comercio marítimo en la región, incluso del comercio con Suecia..$^{58}$ Sus intereses a largo plazo claramente contrastaban con los intereses de los saqueadores, que solo intentaban aprovechar las condiciones favorables para enriquecerse.

Roy observó un auge en el comercio sueco a lo largo de la costa, especialmente en el puerto prusiano de Piława, y le pidió a Wallenstein que considerara si era conveniente impedirlo. Por las razones ya mencionadas, Wallenstein no estaba dispuesto a aceptar esta propuesta. ${ }^{59}$

Cuando el comandante sueco Ryning regresó para continuar bloqueando Wismar, descubrió que la armada imperial había vuelto al puerto y que una parte de los buques ya había sido desmantelada y preparada para invernar. Ryning entregó el comando a Peter Blume, dotado del título de vicealmirante. Al mismo tiempo, su armada fue reforzada. No solo los buques suecos participaron en el bloqueo, sino también cuatro buques del vasallo del rey sueco Jorge Guillerme, elector de Brandeburgo, que habían caído en manos suecas durante el ataque de Gustavo Adolfo II a Piława el 5 de julio de 1626. Sin embargo, a principios de noviembre, la escuadra sueca regresó a Suecia. ${ }^{60}$

Gracias a la salida de los buques suecos, los buques imperiales de Wismar podían operar a lo largo de la costa y monitorizar la navegación, a menos que estuvieran preparados para invernar. Sin embargo, el ataque previsto contra Stralsund finalmente no se realizó. Ya antes, Wallenstein ordenó a su comandante en Pomerania, coronel Hatzfeld, que inutilizase el puerto de Stralsund hundiendo algunos buques enfrente de él. ${ }^{61}$ No obstante, no tenemos ningún informe sobre la ejecución de esta orden.

Hasta fines de 1629, la armada imperial-polaca no realizó ninguna acción. Su inactividad contribuyó a la desmoralización de las tripulaciones. Al comenzar el invierno algunas partes de las tripulaciones abandonaron sus buques por lo que el reclutamiento entre pescadores y gente de mar seguía siendo difícil y las tripulaciones quedaban incompletas. Las tentativas de reclutar marineros

57. Wallenstein al Cristiano IV 29. 11. 1629, NA VL 67/50.

58. Eso está confirmado por muchos documentos. P. ej. cuando los comandantes imperiales detuvieron en Wolgast un buque de Rostock que transportaba cerveza a Estocolmo. Wallenstein ordenó su liberación porque prefería un comercio libre. En relación con esto, WaIlenstein permitió a Wismar la libre exportación de cerveza a Suecia en los buques de Rostock. Rostock a Wallenstein 26. 1. 1629, NA VL 67/52; Armadores de Rostock a Wallenstein 25. 1. 1629, NA VL 67/52; Wallenstein a Stammer 26. 1. 1629, NA VL 67/50; Wallenstein a Mansfeld 20. 2. 1629, NA VL $67 / 50$.

59. Kollmann, Josef, Valdštejn a evropská politika 1625-1630: Historie 1. generalátu. Praga 1999, p. 287.

60. Pertek, Flota polska, pp. 429-430.

61. Wallenstein a Hatzfeld 10. 6. 1629, DBBT IV, n. 781, p. 303. 
de manera violenta no tuvieron mucho éxito, ya que después siguieron deserciones que no podían ser evitadas cuando la armada permanecía en el puerto. Además las deserciones eran la causa de que hubiese disminuido la moral de los marineros restantes. ${ }^{62}$

Cuando los suecos descubrieron que Wallenstein no tenía la intención de intervenir agresivamente contra su comercio naval, estuvieron satisfechos con el status quo. Ambas partes mostraron cierto auto-control porque era más ventajoso que un conflicto abierto, por lo que hubo una tregua armada en el Mar Báltico.

A principios de noviembre de 1629, el emperador ordenó a Wallenstein y a Roy que devolvieran inmediatamente los buques polacos al rey de Polonia, y que retornasen a Gdansk. Informó de que el motivo de su decisión era eliminar todas las dudas sobre su capacidad para garantizar un comercio libre en el Mar Báltico. Dejó claro que no tenía intenciones ofensivas en el mar. ${ }^{63}$ Empero, cuando la orden fue entregada, los buques estaban listos para invernar en Wismar, por lo que la orden no se cumplió. ${ }^{64}$

La decisión antes mencionada de Fernando II fue obviamente relacionada a las actividades de Segismundo III, que estaba muy preocupado por el estado de su armada en Wismar. El rey polaco negociaba no solo con el emperador, sino también con el rey español. El 22 de enero de 1630 recurrió al rey de España y exigió la entrega de sus buques. Esta carta es conocida solo por un extracto minucioso que se conservó en las actas de la reunión del Consejo de Estado. El Consejo discutió sobre ella solo el 15 de junio de 1631 (!), o sea, después de que el barón de Auchy hubiera regresado a Madrid. En la reunión estaban presentes el cardenal Zapata, el conde de Oñate, el marqués de Gelves, el padre Sotomayor y el conde de Castrillo. El rey polaco recordó que había entregado su armada a Felipe IV bien equipada y puesta a punto. También recordó que los buques estaban inactivos, mal utilizados y podrían ser perdidos, y que los funcionarios españoles no querían devolverlos sin orden explícita de su rey. Por lo tanto, solicitó que fuera enviada una carta a Roy ordenándole la entrega de los buques, incluyendo todo el equipamiento militar. Los miembros del Consejo de Estado reconocieron la necesidad de ordenar a Roy que los buques fueran devueltos al rey polaco, evitando la interrupción de las buenas relaciones con él. Sin embargo, Olivares todavía fomentó una idea de una alianza posible entre Dinamarca y Polonia contra Suecia, así como otras posibilidades de la participación española comercial y militar en el Mar Báltico. Finalmente, todas estas consideraciones fueron descartadas a causa del desarrollo desfavorable de la Guerra sueca. ${ }^{65}$

62. Koczorowski, Flota polska, p. 355.

63. Emperador a Wallenstein 1. 11. 1629, NA VL F 67/51 DBBT IV, n. 878, p. 336.

64. Bei der Weiden, Die kaiserliche Ostseeflotte, p. 89.

65. Skowron, Ryszard, Olivares, Wazowie i Baltyk, Polska w polityce zagranicznej Hiszpanii w latach 1621-1632. Cracovia 2002, pp. 242-243, 257-261. 
Sin embargo, la idea de la cooperación de España con Dinamarca fue realizada, por lo menos en el nivel comercial. Gabriel de Roy, después de largos años de negociaciones inútiles con la Hansa, llegó a la conclusión de que las medidas anti-holandesas no podían ser aplicadas en Hamburgo o Lübeck. Por lo tanto, negoció un acuerdo comercial con el rey Cristiano IV en Wismar, pero solo por su voluntad y sin que se informara al rey español o Wallenstein. En virtud de este contrato, Roy se convirtió en el agente español en Glückstadt en Elba, donde comienzó a emitir certificados para todos los bienes que llegaban vía Elba (desde Hamburgo) y Weser (desde Bremen) hasta los puertos ibéricos. A cambio de ello, los daneses podían exportar las mercancías a España también en los buques hechos en las Provincias Unidas. Roy negoció el acuerdo en secreto con Álvaro Dinis, judío portugués, y un experto danés en el comercio ibérico, de manera que los judíos sefardíes de Glückstadt no fueran excluidos del pacto. El tratado provocó considerable oposición de la Hansa, los holandeses y los suecos. Fue una gran sorpresa también para el rey español, que Ilamó a Roy a Madrid en 1631. A pesar de todo, en diciembre de 1632, Roy regresó a Glückstadt y el rey ratificó el tratado. ${ }^{66}$

\section{Otras acciones de la armada en el contexto de la política europea}

El fracaso de las negociaciones de febrero de 1629 en Viena entre el barón de Auchy, como representante de Polonia, y el emperador tuvo gran importancia para el futuro de la armada hispano-polaca. Las negociaciones estaban relacionadas con las propuestas del príncipe polaco Vladislao en noviembre del año anterior. El embajador Aytona también asistió a estas negociaciones. Fernando II consideró interesantes las propuestas del príncipe Vladislao. ${ }^{67}$ Expresó su voluntad de proveer asistencia militar a Polonia contra Suecia en forma de 8000 a 10000 soldados, pero bajo condiciones inaceptables para España. Por lo tanto, estas condiciones efectivamente impidieron la realización del proyecto. Exigieron que Felipe IV se encargara de pagar los gastos necesarios para mantener a las tropas y para que la Armada de Flandes participara en la invasión a Suecia. Esa invasión, sin el apoyo de una poderosa armada y con la perspectiva del tratado de paz con Cristiano IV, representaba un riesgo considerable. El emperador y Wallenstein intentaban principalmente mantener su control sobre Prusia, ya que impedía la entrada del ejército sueco al Imperio. ${ }^{68}$ Por lo tanto, la asistencia militar imperial a Polonia se limitó a la infantería y solo tuvo impacto un poco más tarde. La derrota de las tropas polacas en Górzno el 12 de febrero de 1629

66. Israel, Jonathan I., The Politics of International Trade Rivalry during the Thirty Years War, pp. 541-542.

67. Szelągowski, Adam, O ujście Wisly: Wielka wojna pruska. Varsovia 1905, pp. 24-25.

68. Skowron, Olivares, Wazowie i Baltyk, pp. 243-244. 
provocó una reanudación de las negociaciones entre Polonia y el emperador con la intención polaca de recibir un mayor apoyo militar por parte del emperador. A mediados de marzo, Fernando II le ordenó a Wallenstein que enviara 10000 soldados de su ejército para ayudar a Segismundo III. Wallenstein ofreció incluso 20000 soldados. A mediados de abril de 1629 ordenó a Juan Jorge Arnheim (Arnim) que marchara con 7000 soldados de Stralsund hasta Prusia Real, sin esperar por el tratado de paz con Dinamarca. El número de soldados disminuyó debido a la deserción, pero poco tiempo después Wallenstein envió refuerzos. El número total de soldados imperiales en los servicios polacos es difícil de estimar, pero probablemente nunca excedió los 6000 o 7000 soldados. Arnheim consiguió superar en táctica a las tropas suecas y unirse al ejército polaco. ${ }^{69}$

El 5 de mayo de 1629, se reunió de nuevo la Junta del Mar Báltico cuyos miembros eran el Conde-Duque de Olivares, Ambrosio Spinola, Fernando Girón, Juan de Villela, el marqués de Leganés y el conde de Solre. Su tarea fue analizar la correspondencia que había sido enviada a Madrid por Auchy, Aytona, Roy y Sforza. Esta reunión fue crucial para valorar la futura participación de España en el Mar Báltico y el Mar del Norte. Las cartas de Auchy describían la evolución de las negociaciones en Viena, relativas al plan del príncipe Vladislao de invadir Suecia. Las propuestas del emperador de que el rey Felipe IV cubriera los gastos de mantener el ejército, o enviara la Armada de Flandes, fueron consideradas como inviables. Ambrosio Spinola, marqués de Balbases, se oponía frontalmente a la continuación de estas conversaciones.

La decisión fundamental se refería a una posible base naval española en la isla frisia del Norte, Sylt. Esta propuesta estaba relacionada con el notable éxito de la diplomacia española en otra parte del norte de Alemania. En el otoño de 1628, la Infanta Isabela Ilegó a un acuerdo con Federico III, duque de Schleswig-Holstein-Gottorp, en el cual éste ofreció su puerto de Friedrichstadt en la costa oeste de Schleswig para el comercio español y estaba de acuerdo con excluir a los holandeses y los judíos sefardíes de este comercio. Aceptó también al agente español Quirin Janssens de Flandes en su puerto como observador del comercio. En el verano de 1628 le ofreció a Gabriel de Roy Sylt, la isla frisia del Norte, como una base naval española conveniente para la guerra contra los holandeses. Roy visitó la isla y la consideró

69. El curso de las negociaciones en relación a la ayuda de las tropas imperiales fue descrito minuciosamente por Letošník, Polsko, dům Rakouský a Albrecht, Časopis Českého muzea, 111, 1937, pp. 43-57; Seredyka, Jan, Wezwanie positków cesarskich do Polski w 1629 roku, ZN WSPO, Historia 14, 1977, pp. 87-97; y Duda, Paweł, Działalność oddziałów Hansa Georga von Arnima w Rzeczypospolitej z punktu widzenia nuncjusza papieskiego Antonia Santacrocego, Drozdowski, M. R.; Walczak, W.; Wiszowata-Walczak, K., Od Kijowa do Rzymu, Z dziejów stosunków Rzeczypospolitej ze Stolicą Apostolską i Ukrainą. Bialystok 2012, pp. 511-532. 
idónea. Esto fue confirmado por otros dos expertos independientes venidos de Flandes.

Por miedo al ataque holandés, Roy exigió que 24 buques fueran enviados desde Dunkerque para poder ocupar la base naval mencionada, tres veces más grande de lo que se había sugerido en los planes originales para construir una armada española en el Mar Báltico. Pero Spinola se opuso a estos requisitos. Sostuvo que la Armada de Flandes fuera enviada a España para proteger sus costas y los buques mercantes en el Atlántico. Según su opinión, la llegada de esta armada al Mar Báltico y la ocupación de la isla de Sylt provocarían una reacción dura por parte de Inglaterra, Dinamarca, las Provincias Unidas y Suecia. Esta opinión fue apoyada por todos los miembros de la Junta, incluso Olivares. Por lo tanto, en abril de 1629, una carta fue enviada de Madrid a Bruselas anunciando que el caso de Sylt se pospondría indefinidamente. ${ }^{70}$

Desde el punto de vista polaco, la decisión más importante fue la relativa al destino de la armada, propuesta por Roy. Como se deduce de los dos informes del 5 de mayo, en la corte de Madrid todavía no se conocía la llegada de los buques polacos a Wismar en febrero de 1629. ${ }^{71}$ Roy pidió la subvención de 100000 ducados para nuevos buques porque de 200000 ducados ya enviados le quedaban solo 50000, los cuales tenía que gastar en el mantenimiento de los buques ya construidos y en gastos diarios de 800 escudos. Pero Spinola rechazó rotundamente la posibilidad de continuar construyendo la armada en Wismar. Afirmó que España no obtendría de eso ningún beneficio porque, de todas maneras, la armada sería tan débil que no sería capaz de enfrentarse al enemigo. Según su opinión, tanto al emperador como a las ciudades hanseáticas no les gustaba mucho la actividad de la armada, ya que era contraria a sus intereses comerciales. Sugirió, por lo tanto, que le fuera dada a Roy una orden secreta de no comprar más buques nuevos y no armar los buques ya construidos. Además de eso, quería enviarle solo 50000 ducados para mantener los buques existentes, hasta que se decidiera sobre su destino.

Aunque Olivares tenía una opinión diferente a la de Spinola, reconoció que la situación política era difícil y obligó a España a renunciar a imponer su hegemonía en el Mar Báltico. Las negociaciones fueron influenciadas por el desarrollo de la Guerra de Mantua (1628-1631) y por las noticias de que la participación francesa en esta guerra había crecido ya que España, financieramente agotada, no era capaz de enfrentarla. ${ }^{72}$ Además, La Flota de la Plata española que apresada

70. Las disputas sobre el uso de la Armada de Flandes, que ocurrieron en el abril y mayo de 1629, se analizan más detalladamente Stradling, Robert, La Armada de Flandes: Spanish Maritime Policy and European War 1568-1668. Cambridge, New York, Port/Chester, Melbourne, Sydney 1992, pp. 115-117.

71. Roy, en una carta del 17 de junio de 1629 informó a Madrid sobre la llegada de la armada polaca a Wismar, véase Rodenas Vilar, La política europea, p. 147.

72. Borreguero Beltrán, Cristina, La Guerra de los Treinta Años 1618-1648: Europa ante el abismo. Madrid 2018, pp. 226-230. 
por la escuadra holandesa en la bahía cubana Matanzas (1628), las fuerzas españolas fueron expulsadas de la ciudad holandesa de Hertogenbosch (1929) y los españoles tenían que enfrentar la ofensiva holandesa en Brasil (1630). Todo esto llevaría a España a orientar mejor sus recursos orientando sus prioridades hacía Italia y Flandes, no hacía el Mar Báltico. ${ }^{73}$ Por lo tanto, Olivares decidió que era necesario enviarle a Roy 100000 ducados y darle órdenes de que su armada estuviera lista para salir de Wismar en cualquier momento en dirección a España. Esta decisión debía mantenerse en secreto, especialmente ante Wallenstein. Sin embargo, Olivares consideraba importante mantener buenas relaciones con Polonia. Por lo tanto, 12000 escudos debían ser enviados a Varsovia. Auchy debía persuadir incesantemente al rey polaco para que enviara su armada a Wismar y ofrecerle una posibilidad de venderla a España. ${ }^{74}$

El ejército sueco fue vencido por las tropas polaco-imperiales en la batalla de Trzciana del 27 de junio de 1629; sus acciones militares se limitaron a la defensa de castillos y ciudades. Polonia estaba fatigada por la guerra y Segismundo III entendió que estaba perdiendo el apoyo de España y otras potencias católicas. ${ }^{75}$ Estaba decepcionado porque los países católicos no estaban dispuestos a colaborar con él en la invasión propuesta a Suecia. Por lo tanto, aprovechó la mediación del embajador francés Hércules Girard, barón de Charnacé, el embajador inglés, Roy y la contribución de las Provincias Unidas y Brandeburgo, lo que resultó el 26 de septiembre de 1629 en la tregua de Altmark entre Polonia y Suecia, que duró seis años. ${ }^{76}$

Los términos de la tregua fueron bastante desfavorables para Polonia. Los suecos se quedaron con Braniewo (Braunsberg), Elbląg (Elbing), Tolkmicko (Tolkemit), Klaipeda y Piława. Los dos últimos puertos fueron entregados a Suecia por el elector de Brandeburgo a cambio de Malbork (Mariemburgo, Marienburg), Sztum (Stuhm) y Główa Gdańska (Danziger Haupt). Además de eso, los suecos podían imponer tasas de aduana del 3,5\% sobre el comercio marítimo en Gdansk. Gdansk tuvo que conformarse con tasas del $2 \%$ y hubo de comprometerse a no permitir construir buques en sus astilleros. Bajo las condiciones de la

73. Otero Lana, Enrique, Los corsarios españoles durante la decadencia de los Austrias. Ponferrada 2019, pp. 270-276

74. Skowron, Olivares, Wazowie i Baltyk, pp. 245-246.

75. Ekes, Janusz, Złota demokracja. Varsovia 1987, p. 203, considera el fracaso de las negociaciones con España como una de las causas principales del fin de la tregua con Suecia; también Robert I. Frost acentúa la influencia sustancial de la situación internacional para la conclusión de la paz de Altmark. Frost, Rober I., The Northern Wars: War, State and Society in Northeastern Europe, 1558-1721. Basingstoke 2014, p. 114.

76. Al curso de las negociaciones y a los intermediarios más detalladamente Szelągowski, $O$ ujscie Wisty, pp. 335-342; Cichocki, Marian, Mediacja Francji w rozejmie altmarskim. Cracovia 1928, pp. 101-137; Seredyka, Jan, Rzeczpospolita w ostatmnich latach úanowania Zygmunta III (16291632). Zarys wewnętrznych dziejów politicznych, Opole 1978, pp. 10-51; Serwański, Maciej, Francja wobec Polski w dobie wojny trzydziestoletniej (1618-1648). Poznań 1986, pp. 48-69; Mierzwa, Edward Alfres, Anglia a Polska w pierwszej polowie XVII wieku. Varsovia 1986, pp. 87-113. 
tregua, la armada polaca no podía tener una base naval en Gdansk. ${ }^{77}$ Entonces, Polonia salió de la guerra con Suecia efectivamente derrotada. Se le privó de una armada con la que podría intentar establecer un comercio libre al menos en la bahía de Gdansk, y perdió las tasas de aduana de Gdansk, de las cuales los suecos se beneficiaban bastante. ${ }^{78}$ También pueden ser considerados como ganadores de la guerra polaco-sueca Inglaterra, Francia, las Provincias Unidas y Brandeburgo, o sea los países que querían encaminar el ejército sueco hacia el Imperio donde sucedió la Guerra de los Treinta Años.

Gustavo Adolfo aprovechó el invierno para preparar una campaña al norte de Alemania. Consiguió reunir un ejército que consistía de 35000 soldados (16000 de Suecia, 2800 de Finlandia, 2300 de Estonia y Livonia, 8200 de Stralsund y 16500 de Prusia Real). Sin embargo, el rey necesitaba muchos buques para transportar un ejército tan grande al Imperio, y la construcción de esos buques requería gran esfuerzo. En el transcurso del invierno se reunieron 10 buques de guerra, 16 buques de transporte y 106 pequeñas embarcaciones para transportar las tropas de Suecia, 12 buques de Livonia y 62 buques de Prusia Real. Después de haber ocupado la bahía de Gdansk y las tasas de aduana locales, el siguiente objetivo de la política sueca fue tomar control de la desembocadura del río Óder. ${ }^{79}$

Antes de que el ejército principal de Gustavo Adolfo ocupara la desembocadura del río Óder, la expedición sueca de Stralsund conquistó la isla de Rügen. Los daneses temían que la influencia sueca se ampliara y, por lo tanto, ocuparon la isla de Ruden entre las islas de Rügen y Uznam (Usedom). Pusieron allí una aduana y recaudaron las tasas de los buques que abastecían los puertos de Pomerania. Sin embargo, los daneses no tenían las fuerzas suficientes para adelantar a los suecos en más sitios. En junio de 1630, las tropas suecas estaban listas, al final del mes se embarcaron en 25 buques de guerra y transporte y zarparon del puerto de Älvsnabben, al sur de Estocolmo. El ejército constaba de 10400 soldados de infantería, 1300 jinetes y 425 artilleros. Toda la armada estaba formada por cuatro escuadras, cada una de las cuales constaba de 5 a 8 buques de guerra y de muchos buques de transporte. El buque insignia era Tre Kronor, en el cual navegó Gustavo II Adolfo. La armada sueca se dirigió primero hacia la bahía de Greifswald y ocupó la isla de Greifswalder Oie. Solo entonces, a principios de julio, los soldados desembarcaron en la desembocadura del río Óder y conquistaron la isla de Uznam (Usedom). Siguieron las operaciones ofensivas alrededor de Szczecin (Stettin). ${ }^{80}$

Al mismo tiempo, el rey sueco lideró las negociaciones con los príncipes protestantes destacados -elector de Sajonia y Brandeburgo- para que apoyaran las acciones militares suecas en Pomerania Occidental. La armada sueca podía

77. Czolowski, Marynarka v Polsce, Szkic historyczny. Lwów-Warszawa-Kraków 1922, p. 159.

78. Koczorowski, Flota polska, p. 352.

79. Sveriges Krig 1611-1632, pp. 209-210.

80. Sveriges Krig 1611-1632, pp. 209-210. 
contar con la ayuda de los puertos hanseáticos y especialmente de Stralsund, donde dos armadas suecas tenían su base naval, las escuadras de Peter Blume y Erik Ryning. ${ }^{81}$

La armada imperial-polaca no emprendió ningún contraataque porque no tenía fuerza suficiente. Los buques respectivos eran pocos y estaban mal equipados, además en ese momento casi sin tripulaciones. Efectivamente, Wallenstein pensaba en traer marineros de Istria y Dalmacia. ${ }^{82}$ Por lo tanto, los buques suecos pudieron regresar a sus puertos en Suecia después de que los soldados hubieran desembarcado. Solo la armada de Ryning se quedó cerca de Stralsund para proteger las líneas de comunicación suecas. La escuadra de Blume se encargó de bloquear Wismar y Rostock, que se encontraban bajo el control imperial. ${ }^{83}$

El verano de 1630 fue tranquilo, sin grandes acciones marítimas. Los suecos transportaron sus tropas de Prusia Real sin problema alguno y bloqueaban tanto los buques imperiales en Wismar, como los buques polacos en Gdansk. Las tropas suecas desembarcaron en la desembocadura del río Óder en un momento muy oportuno.

En el campo católico había disputas que llevaron a la renuncia de Wallenstein al cargo de comandante superior del ejército imperial. Todo resultó de un decreto imperial muy precipitado que el emperador había emitido después de la paz de Lübeck. La Liga Católica persuadió a Fernando II, el 6 de marzo de 1629, de publicar el Edicto de Restitución que anuló la secularización de los bienes pertenecientes a la Iglesia Católica, ejecutada por los protestantes antes de la paz de Augsburgo de 1555. Se trataba de 2 arzobispados, 16 obispados y unos cientos de monasterios. Wallenstein advirtió al emperador de que no emitiera el Edicto de Restitución porque temía que los príncipes protestantes, indignados, no se unieran al rey sueco Gustavo Adolfo II. Esta preocupación resultó ser completamente justificada. Sin embargo, los rivales de Wallenstein en la corte de Fernando II intentaban convencer al emperador de que el comandante del ejército imperial tenía demasiada influencia. Finalmente, la asamblea electoral del 13 de agosto de 1630 privó a Wallenstein de su mando del ejército imperial. El elector bávaro Maximiliano se destacó como el mayor crítico de Wallenstein, porque no le gustaba el aumento de su poder. ${ }^{84}$ Wallenstein recibió este mensaje con resignación y finalmente proclamó que había renunciado a su jefatura e informó a sus coroneles de la decisión el 13 de septiembre de $1630 .{ }^{85}$ En teoría se quedó con el cargo del comandante de la armada, pero en realidad

\footnotetext{
81. Koczorowski, Flota polska, p. 358.

82. Bei der Weiden, Die Kaiserliche Ostseeflotte, p. 86.

83. Koczorowski, Flota polska, p. 358

84. Kollmann, Valdštejn, pp. 381-382.

85. Kollmann, Valdštejn, p. 382.
} 
fue sustituido por Gabriel de Roy. ${ }^{86}$ Una de sus últimas medidas fue la orden de fortalecer las fortificaciones de Wismar y retirar a los jinetes a la ciudad. ${ }^{87}$ Kaspar von Gramb se hizo cargo de la defensa de la ciudad. ${ }^{88}$

Sin embargo, la situación en la ciudad no se desarrolló bien. En octubre de 1630, la guarnición sufría de varias enfermedades y todos los días morían de 10 a 15 soldados. No había comida, ni mechas combustibles. Se acusaba la falta de soldados y marineros. ${ }^{89}$ Además de eso, Gabriel de Roy informó el 4 de noviembre a Wallenstein de que había recibido una orden del rey español de volver el mes siguiente a España. ${ }^{90}$

Un marinero desertor de Lübeck que logró escapar de Wismar describió el estado de la armada imperial-polaca como deprimente. Si los marineros podían escapar de la ciudad, se confirmaba que Wismar como base naval estaba paralizada. Los espías suecos penetraban en la ciudad y muchos traidores alemanes planeaban tomarla. El plan consistía en un desembarque de los soldados en una playa cerca de la ciudad y un ataque simultáneo por mar y en tierra. ${ }^{91}$

Sin embargo, el 28 de noviembre de 1630, la armada imperial aprovechó una ocasión en que los buques suecos Mänen, Regnbogen, Papegojan y Jungfrun salieron a Rostock. En total cuatro buques, encabezados por Król Dawid, zarparon del puerto. La escuadra se encontraba al noreste de la isla de Poel, en la bahía de Wismar, donde atacó un convoy sueco compuesto por buques mercantes y auxiliares. Aunque los buques suecos consiguieron escapar, los buques imperiales y polacos los perseguían. El buque Król Dawid se separó de la armada y el 23 de diciembre fue atacado por la escuadra de Peter Blume. Los buques suecos cortaron su camino hacia Wismar y la obligaron a buscar refugio en Travemünde, en la bahía de Lübeck. ${ }^{92}$ Los suecos bloquearon el puerto y le impidieron volver. Gustavo Adolfo, con ayuda de su embajador en Hamburgo, Juan Adler Salvius, intentaba convencer a Lübeck de que le entregara el buque imperial. Sin embargo, Lübeck lo rechazó y se quedó con el buque como compensación por sus propios buques previamente confiscados. Por lo tanto,

86. Lorentz, Ottokar, Briefe Wallensteins, meistenheils über Meklenburg, aus der Zeit von 1627 bis 1630, Jahrbücher des Vereins für Mecklenburgische Geschichte und Altertumskunde, 40, 1875, n. 25, p. 111.

87. Wallenstein a Wengersky 14. 9. 1630, NA VL F 6750, Toegel, Miroslav (ed.), Documenta Bohemica Bellum Tricenale Illustrancia, vol. V: Die schwedische Krieg und Wallensteins Ende. Praga 1977, DBBT V, n. 2, p. 21.

88. Wallenstein a Kaspar von Gramb 14. 9. 1630, NA VL F 67/50, DBBT V, n. 3, p. 21.

89. Wengersky a Wallenstein 14. 10. 1630, NA VL F 67/52, DBBT V, n. 30, p. 30.

90. Roy a Wallenstein 4. 11. 1630, NA VL F 67/52, DBBT V, n. 40, p. 33.

91. Un plan extenso está publicado en su totalidad por Wiegandt, Max, Wismar im Dreissigjährigen Kriege, Jahrbücher des Vereins für Mecklenburgische Geschichte und Altertumskunde, vol. 82, 1918, pp. 1-126, odkaz pp. 122-126.

92. Sveriges Krig 1611-1622, pp. 219-220. 
la armada sueca tuvo que conformarse con haber conseguido eliminar el mejor buque de la armada imperial..$^{93}$

Después del invierno, que los comandantes de la armada polaco-imperial no aprovecharon para mejorar las capacidades guerreras de sus buques, los suecos comenzaron su campaña de primavera de 1631 con un bloqueo de los puertos Kolobrzeg (Kolberg) y Greifswald. Mientras tanto, a principios de 1631, Roy se fue a España y fue reemplazado en Wismar por Jacques de Febure. ${ }^{94}$

El 18 de marzo de 1631, la armada imperial-polaca aprovechó el hecho de que los suecos todavía no habían comenzado un nuevo bloqueo de Wismar, y tres buques y una barcaza emprendieron una acción que resultó en la captura de dos buques de Lübeck. Febure no pudo atestiguar que esos buques realmente transportaban contrabando para los suecos. Además de eso, no quería empeorar aún más las ya malas relaciones con Lübeck y, por lo tanto, ordenó liberar ambos buques. ${ }^{95}$

No obstante, los suecos estaban preocupados por la acción anteriormente mencionada de la armada imperial, y enviaron una escuadra del vicealmirante Hans Hanson con la misión de bloquear Wismar. Cuando el 29 de septiembre de 1631 una armada sueca, formada por 20 buques pequeños, apareció enfrente de la ciudad, no causó ninguna respuesta. Al día siguiente, siete buques suecos cerraron el puerto y tras un día se les unió el resto de la armada. Esto llevó a la armada imperial-polaca nuevamente a la inactividad, lo que socavó aún más su capacidad guerrera. En ese momento, un círculo formado por las tropas suecas se estaba cerrando en torno a Wismar. Los defensores retiraron los cañones de la mayoría de los buques y los colocaron en las murallas. El rey sueco le encargó al general Ake Tott atacar Wismar con las mejores tropas suecas. Su tarea era tomar esta ciudad en la que la armada enemiga estaba escondida. En ese momento se trataba de 12 galeones y una pinaza. Varias embarcaciones auxiliares debían ayudar al bloqueo del puerto, porque podían maniobrar fácilmente en el río cercano gracias a la baja línea de flotación. Con su ayuda fue capturado el buque polaco Tygrys a una distancia de 9 millas del puerto. Al llegar a Wismar ese buque tenía 30 cañones, pero en ese momento ya quedaban solo $22 .{ }^{96}$

La capacidad defensiva del ejército imperial en la ciudad disminuía gradualmente. El 19 de octubre las tropas imperiales evacuaron la isla de Poel en la bahía de Wismar. Su ataque contra las tropas de Ake Tott fue repelido sangrien-

93. Koczorowski, Flota polska, p. 360.

94. Schröder, Dietrich, Kurze Beschreibung der Stadt und Herrschaft Wismar. Wismar 1743, p. 190.

95. Koczorowski, Flota polska, p. 361.

96. Koczorowski, Flota polska, p. 225; Wiegandt afirmó que en Tygrysu se quedaron solo 7 cañones. 
tamente. El 5 de noviembre, el ejército sueco comenzó a bombardear la ciudad, lo que resultó en 16 buques y 12 botes incendiados. La guarnición de Wismar, bajo el mando del coronel Kaspar von Gramb luchó valerosamente, pero estaba claro que no podía defender la ciudad. Las negociaciones llevaron a una tregua y luego a una rendición firmada el 22 de enero de 1632. El vicealmirante Erik Ryning capturó los 13 buques polacos e imperiales restantes. Además de eso, dos buques en construcción cayeron en manos de los suecos. Ellos completaron estos buques inacabados y los incorporaron a su armada. Los 14 buques imperiales y polacos ya mencionados, los cuales habían sobrevivido al ataque sueco, compartieron el mismo destino. Recibieron los nombres siguientes: Delfinen (antiguo Delfin), Fenix (antiguo Feniks), Meerweib (antigua Panna Wodna), Meerman (antiguo Wodnik), Vita Hunden (antiguo Bialy Pies), Noe Ark (antiguo Arka Noego), Sankt Jacob (antiguo Święty Jakub), Salvator (antiguo König Caspar), Sankt Mikael, Maria Rekompens (antigua Maria Recompens), Fölängaren (antiguo Vorlänger), Hans von Wismar a Muskijl. ${ }^{97}$ Tygrys, capturado anteriormente, fue incorporado a la armada sueca bajo el nombre Tigern. Febure intentó escapar, pero sin éxito.

La pérdida de los buques en Wismar provocó gran indignación del lado polaco. Después de la conquista de Wismar, Segismundo III envió sus representantes a Gdansk para contar todas las pérdidas. El 15 de junio de 1632 se elaboró un inventario que más tarde sirvió como base para las demandas polacas ante Dinamarca, Lübeck, España y Suecia. ${ }^{98}$ Luego el soberano polaco comenzó a negociar con estos países la posibilidad de devolver los buques perdidos. ${ }^{99}$ Después de la muerte de Segismundo III en 1632, su hijo y sucesor Vladislao IV continuó negociando. Sin embargo, estas negociaciones no tuvieron éxito y convencieron al rey de que sería mejor pedir una indemnización por los buques capturados. La corte española le prometió al rey que pagaría una compensación financiera, pero sus promesas nunca fueron cumplidas. ${ }^{100}$ Entonces, todos los buques enviados a Wismar quedaron irremediablemente perdidos.

\section{Conclusiones}

La armada imperial nunca contó con tantos buques como para igualar a las armadas enemigas. El sueño de Wallenstein de la dominación marítima no se cumplió. Crear una fuerza naval considerable en tan poco tiempo fue para Wallenstein una tarea sobrehumana porque le faltaban recursos financieros.

97. Sveriges Krig 1611-1632, p. 226, anexo 11.

98. Pertek, Flota Polska, p. 432.

99. Segismundo III requirió del rey danés Cristiano IV compensaciones por los buques de los mercaderes de Gdansk y también por los buques confiscados durante la expedición contra Elfsborg.

100. Szelągowski, Rozklad Rzeszy, p. 65. 
Aunque el número de buques imperiales era pequeño, es necesario apreciar que Roy consiguió comprar o construir por lo menos cierta cantidad, a pesar de todos los obstáculos. Esta armada pequeña tenía una cierta potencia de fuego y, en conjunto con la armada polaca, representaba un poder marítimo que no podía ser subestimado. Por supuesto, no era comparable con las armadas escandinavas, la danesa y la sueca, pero suponía un cierto riesgo para ellas. La armada del rey Cristiano IV tenía unos 15 grandes buques de guerra. La armada sueca consistía de 59 unidades en 1629: 8 buques grandes, 21 buques medianos, 29 embarcaciones pequeñas y un buque de carga. ${ }^{101}$ También es necesario tener en cuenta la posibilidad de que esta armada imperial-polaca obtuviera el apoyo de la Armada de Flandes, algo que Wallenstein deseaba desde su llegada al Mar Báltico.

Todos los costes de creación y mantenimiento de esta pequeña armada fueron soportados por la Corona española. Ni el emperador ni Wallenstein contribuyeron a ella con un solo centavo. No hay duda, por lo tanto, de a quién pertenecía la armada. Por otro lado, su construcción y manutención dependían de Wallenstein como comandante superior con el título de "General del Mar Océano y Mar Báltico" y de sus comandantes subordinados. La designación "española" tiene, por consiguiente, la misma justificación que "imperial". Sin embargo, debe añadirse que si el emperador hubiera fornecido por lo menos algún dinero, podría haberse hecho más. Del lado español no se trataba de un regalo, sino solo de un préstamo para el emperador porque en Madrid estaban convencidos de que los buques reforzarían la Armada de Flandes algún día en el futuro, quizás después del final de la guerra con Dinamarca y Suecia. Por la construcción de esta armada, España solo cumplió su promesa, dada anteriormente al rey polaco y al emperador, de que enviaría 24 buques de guerra al Mar Báltico, o que los construiría o compraría. Para Wallenstein, como duque de Mecklemburgo, era ventajoso que esta armada estuviera anclada en Wismar, un puerto en Mecklemburgo. No estaba obligado a pagar absolutamente nada y podría usarla para defender a Mecklemburgo o para estimular el comercio local. La ubicación de la armada en Wismar era necesaria también en el período posterior al fin de la paz de Lübeck. Fue consecuencia de la hostilidad de la armada sueca, en otras palabras, de la guerra no declarada con Suecia, y de la amenaza procedente de Stralsund. El tamaño e importancia de la armada dependían de los medios financieros que le habían dado. Si le hubieran dado más finanzas, la armada podría haber aumentado considerablemente en el corto plazo.

Madrid y Bruselas rechazaron enviar sus buques de guerra al Mar Báltico con una justificación realista, ya que eran necesarios para proteger la costa de Flandes. En la fase siguiente, exigieron en cambio que el ejército imperial entra-

101. Zettersten, Svenska flottans historia, p. 373; Bei der Weiden, Die kaiserliche Ostseeflotte, p. 87. 
ra en guerra contra las Provincias Unidas, lo que Wallenstein no quería permitir antes de que la guerra con Dinamarca acabase. Después de que concluyera la paz de Lübeck con Dinamarca en 1629, la armada perdió el derecho formal a su existencia. La amenaza danesa desapareció y la compañía comercial hanseático-ibérica, cuya protección debía ser asegurada por la armada, no fue creada. Mientras tanto, Madrid renunció a esta idea. Sin embargo, la guerra con Suecia surgió rápidamente y la comunicación difícil entre el emperador y el rey polaco por un lado, y el rey español por otro, llevaron a principios de 1632 a la pérdida de los buques tanto para el lado español como para la Corona polaca.

La armada imperial tenía dos puntos débiles. En primer lugar, carecía de un almirante competente con experiencia en la navegación en el Mar Báltico y en combates navales. Los buques no tenían tripulaciones permanentes porque, por razones económicas, solo se contrataban para el verano y se despedían en el invierno. Esta práctica era común en esa época pero, a consecuencia de eso, la armada tenía un carácter esencialmente temporal. Finalmente, los buques estaban mal equipados.

A fines de 1629 era obvio que los espléndidos planes marítimos que habían sido concebidos en la corte española y en los que se ponían tales esperanzas se estaban desvaneciendo. Hay que decir que el emperador y Wallenstein los respaldaban, pero el proyecto fracasó debido a la resistencia de las ciudades hanseáticas y a la inconsistencia de la política española. Los españoles no establecieron su Almirantazgo en el Mar Báltico, ni enviaron allí una armada grande, ni establecieron una compañía comercial monopólica. No hicieron muchos esfuerzos para hacer cumplir sus planes y se dejaron desanimar por la opinión adversa de la Hansa.

La renuncia española a continuar financiando el proyecto de manera significativa estuvo condicionada por el hecho de que Wallenstein obtuvo un control real sobre la armada. Wallenstein no quería usarla en la guerra contra los holandeses, el principal enemigo español. Además, las negociaciones con la Hansa no dieron fruto alguno porque la Hansa había rechazado no solo la idea de una sociedad hanseático-ibérica, sino también la aplicación de todos los instrumentos de la política española contra los holandeses. Los logros parciales que los españoles alcanzaron en colaboración con el duque de Schleswig-HolsteinGottorp Frederico III y con el rey danés Cristiano IV no tuvieron efectos notables porque fueron logrados demasiado tarde. España, económicamente agotada y ocupada con los conflictos militares en Italia y en otras partes del mundo, no podía utilizarlos para implementar sus planes originales.

Sin duda la desconfianza hacia Wallenstein tuvo un papel importante porque los españoles pensaban que perseguía exclusivamente sus propios objetivos. A pesar de que era así, Walllenstein siempre se basaba en los cálculos realistas y, paradójicamente, fue la única persona que nunca dejó de creer en la posibilidad de la creación de una compañía comercial hanseático-ibérica. Aunque esta finalmente no fue fundada, él quería beneficiarse del comercio báltico 
como duque de Mecklemburgo y apoyaba a sus ciudades en ese sentido. Si se le hubiera permitido permanecer en Mecklemburgo más tiempo, no hay duda de que habría intentado aumentar la importancia de las ciudades de Wismar y Rostock para que atrajeran una parte considerable del comercio báltico. Sin duda, la armada imperial le habría ayudado.

\section{Bibliografía}

Bei der Weiden, Helge, Wallenstein und die kaiserliche Ostseeflotte 1627-1632 aus tausend Jahren mecklenburgischer Geschichte. Colonia-Viena 1979.

Borreguero Beltrán, Cristina, La Guerra de los Treinta Años 1618-1648: Europa ante el abismo. Madrid 2018.

Cichocki, Marian, Mediacja Francji w rozejmie altmarskim. Cracovia 1928.

Czolowski, Marynarka v Polsce, Szkic historyczny. Lwów-Warszawa-Kraków 1922.

Duda, Paweł, "Działalność oddziałów Hansa Georga von Arnima w Rzeczypospolitej z punktu widzenia nuncjusza papieskiego Antonia Santacrocego", Drozdowski, M. R.; Walczak, W.; Wiszowata-Walczak, K., Od Kijowa do Rzymu, Z dziejów stosunków Rzeczypospolitej ze Stolicą Apostolską $i$ Ukrainą. Bialystok 2012.

Ekes, Janusz, Złota demokracja. Varsovia 1987.

Frost, Rober I., The Northern Wars: War, State and Society in Northeastern Europe, 1558-1721. Basingstoke 2014.

Hroch, Miroslav, Valdštejnova politika v severním Německu v letech 1629-1630, Sborník historický 5, 1957, pp. 203-228.

Chlumecký, Petr Jiří, Die Regesten oder chronologische Verzeichnisse der Urkunden in den Archiven zu Iglau, Trebitsch, Triesch, Gross.Bitesch und Pirnitz, sammt den noch ungedruckte Briefen Kaisers Ferdinand der Zweiten, Albrechts v. Waldstein und Romboalds Grafen Collalto. Brno 1856.

Israel, Jonathan I. Empires and Entrepots: Dutch, the Spanish Monarchy and the Jews, 1585-1713, London, Ronceverte 1990.

Israel, Jonathan I., "The Politics of International Trade rivalry during the Thirty Years War: Gabriel de Roy and Olivares' Mercantilist Proyects, 1621-1645". The International History Review 8 (4), 1986, pp. 517-549.

Khevenhüller, Franz Christoph, Annales Ferdinandei, Annales Ferdinandei Oder Wahrhaffte Beschreibung Kaysers Ferdinandi Des Andern, Mildesten Gedächtniß, Geburth, Aufferziehung und bißhero in Krieg und Friedens-Zeiten vollbrachten Thaten, geführten Kriegen, und vollzogenen hochwichtigen Geschäfften. 12. ..., darinnen Kaeysers und Koenigs Ferdinand ... Handlungen wegen ... Kriege in Deutschland ... wie auch alle denckwuerdige Geschi- 
chte ... vom Anfange des 1632. biß zu Anfang des 1637. Jahrs beschrieben werden, vol. 11, 1726.

Koczorowski, Eugeniusz, Flota polska v latach 1587-1632. Varsovia 1973.

Kollmann, Josef, Valdštejn a evropská politika 1625-1630: Historie 1. generalátu. Praga 1999.

Letošník, Václav, "Polsko, dům Rakouský a Albrecht z Valdštejna 1626-1629", Časopis Českého muzea 111, 1937, pp. 211-247.

Líva, Václav, Prameny $k$ dějinám třicetileté války - Regesta Fondu Militare, Parte IV. 1626-1635. Praga 1953.

Lorentz, Ottokar, "Briefe Wallensteins, meistenheils über Meklenburg aus der Zeit von 1627 bis 1630", Jahrbücher des Vereins für Mecklenburgische Geschichte und Altertumskunde, 40 (25), 1875.

Mierzwa, Edward Alfres, Anglia a Polska w pierwszej polowie XVII wieku. Varsovia 1986.

Mörner, Magnus, "Las relaciones Hispano-Suecas ante la paz de Wesfalia", Historiar: Revista trimestral de Historia 1, 1999, pp. 124-140.

Navarro Bonilla, Diego, Cartas entre espías e inteligencias secretas en el siglo de los validos, Juan de Torres-Gaspar Bonifaz, 1632-1638. Madrid 2007.

Opel, Julius Otto, Der niedersächsisch-dänische Krieg, vol. I-III. Magdeburg 1872-1894.

Otero Lana, Enrique, Los corsarios españoles durante la decadencia de los Austrias. El corso español del Atlántico peninsular en el siglo XVII (1621-1697). Ponferrada 2014.

Pertek, Jerzy, "Flota polska w Wismarze (1629-1632)", Przegłąd Zachodni 10 (7/8), 1954, pp. 415-434.

Rodenas Vilar, Rafael, La política europea de España durante la guerra de los Treinta Años (1624-1630). Madrid 1967.

Seredyka, Jan, Wezwanie positków cesarskich do Polski w 1629 roku, ZN WSPO. Historia 14, 1977.

Serwański, Maciej, Francja wobec Polski w dobie wojny trzydziestoletniej (1618-1648). Poznań 1986.

Schröder, Dietrich, Kurze Beschreibung der Stadt und Herrschaft Wismar. Wismar 1743.

Skowron, Ryszard, Olivares, Wazowie i Baltyk, Polska w polityce zagranicznej Hiszpanii w latach 1621-1632. Cracovia 2002.

Stradling, Robert, La Armada de Flandes: Spanish Maritime Policy and European War 1568-1668. Cambridge, New York, Port/Chester, Melbourne, Sydney 1992.

Szelągowski, Adam, O ujście Wisly: Wielka wojna pruska. Varsovia 1905. 
Wahrlich, Bernd, Der Dreißigjährige Krieg in Selbstzeugnissen, Chroniken und Berichten, Mansfeld-Vorderort zu Bornstedt, Philipp (V.) Graf von (fuente electrónica). 2011. Disponible en: http://www.30jaehrigerkrieg.de/mansfeld-vorderort-zu-bornstedt-philipp-v-graf-von/

Wiegandt, Max, "Wismar im Dreissigjährigen Kriege", Jahrbücher des Vereins für Mecklenburgische Geschichte und Altertumskunde 82, 1918, pp. 1-126.

Zettersten, Axel, Svenska flottens historia áren 1522-1634. Estocolmo 1890. 